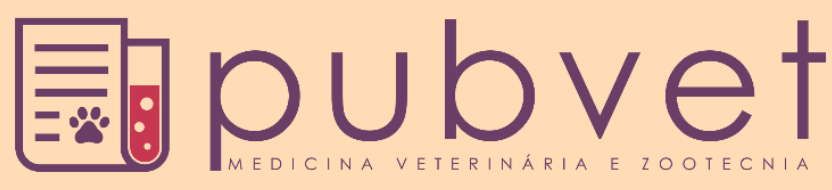

https://doi.org/10.31533/pubvet.v13n11a458.1-6

\title{
Determinação da qualidade imunológica do colostro de cadelas por refratometria
}

\author{
Suzane de Cássia Moraes Albuquerque ${ }^{10}$, Cassia Batista Silva ${ }^{1 \bullet}$, Francisca Elda Ferreira \\ $\operatorname{Dias}^{20}$, Cleidson Manoel Gomes da Silva ${ }^{\circ}$, Mônica Arrivabene ${ }^{4}$, Aníbal Pereira de \\ Souza $^{5 \bullet}$, Samara Dias Cardoso Rodrigues ${ }^{2}{ }^{\bullet}$, Tânia Vasconcelos Cavalcante ${ }^{4 *} \bullet$ \\ ${ }^{I}$ Iniciação Científica Voluntária, Curso de Medicina Veterinária, CCA, campus de Teresina, UFPI. \\ ${ }^{2}$ Professora da Escola de Medicina Veterinária e Zootecnia, UFT, campus de Araguaína, Tocantins. Mestranda do PPGSASPT da Escola de \\ Medicina Veterinária e Zootecnia, UFT. \\ ${ }^{3}$ Professor da Universidade Federal do Sul e Sudeste do Pará, Xinguara, Pará. \\ ${ }^{4}$ Professora da Universidade Federal do Piauí, Depto de Clínica e Cirurgia Veterinária, CCA, campus de Teresina, UFPI. \\ ${ }^{5}$ Zootecnista autônomo \\ *Autor para correspondência: cavalcante.tv@gmail.com
}

Resumo. A transferência de imunidade em cadelas gestantes é pouco eficiente, apenas 5 a $10 \%$ dos anticorpos são transferidos através da placenta aos seus filhotes. Portanto, os recém-nascidos são dependentes da transferência de anticorpos através de colostro, possuindo seu sistema imune pouco desenvolvido. Sabe que as doenças neonatais imediatas representam um grande desafio para o clínico veterinário, devido haver alta correlação entre a mortalidade neonatal canina e a menor concentração de imunoglobulinas nos seus primeiros dias de vida. Dessa forma, torna-se indispensável a ingestão adequada de colostro logo após o parto de cadelas. Portanto, objetivou-se com este estudo avaliar a qualidade do colostro por refratometria digital (\% Brix) nos diferentes pares de tetas de cadelas após parto normal e cesariana. Utilizaram-se dez cadelas de raças distintas, idades reprodutivas e caracterização corpórea variada, nas quais as coletas se deram nas 24 horas após o parto, com fêmeas submetidas partos normais $(n=4)$ ou cesarianas $(n=6)$. As amostras de colostro após o parto normal ou cesariana foram avaliadas pela concentração de proteína total (PT) pela técnica de Refratometria Digital (\%Brix). Para análise estatística utilizouse ANAVA seguido do teste de Tukey $(\mathrm{P}<0,05)$. As médias de \%Brix por refratometria digital do colostro, coletadas a partir de cadelas que tiveram parto normal ou cesariana foram $28,22 \pm 1,38$ e 27,08 $\pm 1,65$ respectivamente. Não foi observado efeito do tipo de parto, bem como do tipo de teta (direita x esquerda) sobre o valor de proteína total avaliada por refratometria. Em conclusão, o método de refratometria utilizado neste estudo demonstrou ser prático, apresenta custo baixo e de fácil realização, podendo ser facilmente utilizado. Além disso, permitiu verificar que a qualidade do colostro nos diferentes pares de tetas de cadelas não apresenta diferenças significativas e não sofre efeito do tipo de parto.

Palavras chave: Cão, glândula mamária, imunoglobulina G, refratometria

\section{Determination of the immunological quality of bitch colostrum by refractometry}

Abstract. Transfer of immunity in pregnant bitches is inefficient, only 5 to $10 \%$ of the antibodies are transferred through the placenta to their offspring. Therefore, newborns are dependent on the transfer of antibodies through colostrum, having a poorly developed immune system. He knows that immediate neonatal diseases represent a great challenge for the veterinarian, since there is a high correlation between canine neonatal mortality and the lower concentration of immunoglobulin in their first days of life. Thus, adequate colostrum 
intake immediately after delivery of bitches is essential. Therefore, the objective of this study was to evaluate the quality of colostrum by digital refractometry (\% Brix) in the different pairs of teats of bitches after normal delivery and cesarean section. Ten bitches of different breeds, reproductive ages and varied body characterizations were used, in which the samples were collected in the 24 hours after calving, with females submitted to normal deliveries $(n=4)$ and cesareans $(n=6)$. Colostrum samples after normal delivery or cesarean delivery were evaluated by total protein concentration (PT) using the Digital Refractometry (\% Brix) technique. Statistical analysis was used ANAVA followed by the Tukey test $(\mathrm{P}<0.05)$. The means of $\%$ Brix by digital refractometry of colostrum, collected from bitches that had normal delivery and cesarean were $28.22 \pm 1.38$ and $27.08 \pm 1.65$ respectively. No effect of the type of delivery, as well as the type of theta (right $\mathrm{x}$ left) on the total protein value evaluated by refractometry was observed. In conclusion, the refractometry method used in this study proved to be practical, low cost and easy to perform and can be easily used. In addition, it was verified that the quality of colostrum in the different pairs of teats of bitches does not present significant differences and does not suffer from the type of delivery.

Keywords: Dog, glad mammary, immunoglobulin G, refractometry

\section{Determinación de la calidad inmunológica del calostro de hembras caninas por refractometría}

Resumen. La transferencia de inmunidad en hembras caninas gestantes es poco eficiente, sólo entre el 5 y el $10 \%$ de los anticuerpos se transfieren a través de la placenta a su descendencia. Por lo tanto, los recién nacidos dependen de la transferencia de anticuerpos a través del calostro, que poseen su sistema inmunológico poco desarrollado. Se sabe que las enfermedades neonatales inmediatas representan un gran desafío para el médico veterinario, debido a una alta correlación entre la mortalidad canina neonatal y la menor concentración de inmunoglobulinas en sus primeros días de vida. De tal modo que se torna indispensable la correcta ingesta de calostro poco después del parto. Por lo tanto, el objetivo de este estudio fue evaluar la calidad del calostro por refractometría digital (\% Brix) en los diferentes pares de mamas de hembras caninas después del parto normal y cesárea. Se utilizaron diez de hembras de razas distintas, edades reproductivas y condición corporal variada, en las que las colectas tuvieron lugar en las 24 horas posteriores al parto, con las hembras presentando partos normales (n-4) y cesáreas (n-6). Las muestras de calostro después del parto normal o la cesárea se evaluaron mediante la concentración total de proteínas (PT) mediante la técnica de Refractometría Digital (\%Brix). Para el análisis estadístico, ANAVA fue utilizado seguido de la prueba de Tukey $(\mathrm{P}<0.05)$. Los promedios de \%Brix por la refractometría digital de calostro, recogidos de la administración normal y la cesárea, fueron de $28,22 \pm 1,38$ y $27,08 \pm 1,65$, respectivamente. No se observó efecto del tipo de parto, así como el tipo de mama (derecha $\mathrm{x}$ izquierda) sobre el valor proteico total evaluado por la refractometría. En conclusión, el método de la refractometría utilizado en este estudio demostró ser práctico, presentó bajo costo y se puede utilizar fácilmente. Además, permitió verificar que la calidad del calostro en los diferentes pares de mamas no presenta diferencias significativas y no tiene efecto del tipo de entrega.

Palabras clave: Perro, glándula mamaria, inmunoglobulina G, refractometría

\section{Introdução}

Os neonatos caninos nascem hipogamaglobulinêmicos. Na gestação as cadelas passam apenas de 5 a $10 \%$ dos anticorpos pela placenta aos seus filhotes (Miagava et al., 2015), sendo o colostro sua principal fonte de imunoglobulinas (Mila et al., 2015). Assim que acontece o parto, a mãe disponibiliza o colostro, que é de vital importância para proporcionar aos recém-nascidos a imunidade passiva, concedida na forma de imunoglobulinas que serão absorvidas pela mucosa intestinal do filhote dando a ele proteção diante de algumas doenças infecciosas (Tôrres \& Zimmermann, 2017). No entanto, a 
otimização da transferência passiva de imunoglobulinas requer que a ingestão do colostro ocorra prontamente nas primeiras quatro horas que ocorre a maior absorção intestinal de anticorpos $\operatorname{IgG}$, diminuindo até cessar por volta das 24 horas de vida, fenômeno conhecido por barreira intestinal (Chastant-Maillard et al., 2012).

Em muitas espécies tem sido demonstrado que a adequada transferência de imunidade passiva materna pela ingestão do colostro é crucial para sobrevivência e controle de doenças em recém-nascidos (Santos et al., 1994; Santos et al., 1995; Vallet et al., 2013). Este tipo de estudo possui uma grande relevância no âmbito da neonatologia canina, visto que a falha da transferência de imunidade passiva torna os neonatos susceptíveis a infecções e, consequentemente até mesmo a morte precoce (Grongnet et al., 1996). A falha na transferência de imunidade em neonatos caninos é difícil de ser diagnosticada de forma direta, pois os exames disponíveis para mensuração de imunoglobulinas são de difícil execução e de resultados demorados, prejudicando a eficácia das intervenções do médico veterinário (Tôrres \& Zimmermann, 2017). Uma alternativa para estas limitações tem sido a utilização do refratômetro (\%Brix), que permite a avaliação da qualidade do colostro e sólidos de leite com precisão aceitável. Entretanto, não mede a quantidade $\mathrm{IgG}$ e sim proteína total, do qual, cujo valor obtido indica a proteína total nos soros dos animais (Quigley et al., 2013).

O refratômetro (\% Brix) é um instrumento versátil já que pode ser utilizado tanto no colostro como no soro. Este utiliza uma escala Brix que é usada para medir o teor de açúcar de uma solução. Esta escala tem sido adaptada para a utilização em explorações de bovinos, tendo-se demonstrado que possui uma boa correlação entre a percentagem Brix (\% Brix) e a concentração de Ig G tanto no colostro como no soro de bovinos e equinos (Deelen et al., 2014). O método é baseado no simples fato de que valores baixos de proteína total refletem uma falha na transferência de anticorpos maternos (Feitosa, 2014). Neves et al. (2018) estimaram as correlações entre os níveis de imunoglobulinas pelo Teste de Sulfato de Zinco (TSZ) e Refratometria em colostro de ovelhas coletados em diferentes momentos pós-parto, verificaram que os mais altos valores de correlação foram observados entre o \% Brix em amostras de colostro coletado às 6 horas pelo TSZ (0.66) e 24 horas (0.83). Portanto, objetivou-se com este estudo avaliar a qualidade do colostro por refratometria digital (\% Brix) nos diferentes pares de tetas de cadelas após parto normal ou cesariana.

\section{Material e métodos}

Todos os procedimentos realizados neste experimento foram aprovados pela Comissão de Ética no Uso de Animais da Universidade Federal do Piauí (CEUA/UFPI), no Centro de Ciências Agrárias sob número 347/17.

Foram utilizadas dez cadelas de raças distintas, idades reprodutivas e caracterização corpórea variada, nas quais as coletas se deram nas 24 horas após o parto, sendo as fêmeas submetidas aos partos normais $(n=4)$ e cesarianas $(n=6)$.

As cadelas pertenciam a cinco raças diferentes: Yorkshire $(n=5)$, SRD $(n=3)$, Maltês $(n=1)$, Pinscher $(\mathrm{n}=1)$ e Dálmata $(\mathrm{n}=1)$. O número total de filhotes nascidos (tamanho da ninhada) foi anotado. As tetas foram limpas separadamente com cuidado, com água destilada e seca com gaze ou algodão, antes da coleta. Cada teta foi coletada separadamente. Cerca de uma gota de colostro foi obtida de cada teta por uma massagem suave da glândula mamária e subsequentemente ordenha manual. Os filhotes não tiveram acesso à mãe ao longo da duração da coleta de amostras.

As amostras de colostro coletadas dentre nas 24 horas pós-parto normal ou cesariana, e avaliadas para uma estimativa de concentração de proteína total (PT) pela técnica de refratometria digital (\%Brix) a fim de estimar a concentração de imunoglobulinas G. Refratometria mede a concentração de sólidos dissolvidos na solução. No caso de um refratometro Brix, uma pequena quantidade de colostro é colocada sobre o prisma e a placa de luz está fechada. O colostro é então distribuído uniformemente pelo prisma. O refratômetro é mantido na direção de uma fonte de luz e o desvio ou refração da luz é avaliada em uma escala como uma pontuação percentual. O colostro com uma baixa quantidade de sólidos dissolvidos (ou seja, baixo nível IgG) terá uma menor quantidade de dispersão de luz e uma menor pontuação percentual. O colostro com quantidades elevadas de sólidos dissolvidos (ou seja, altos níveis de IgG) irá causar dispersão de mais luz e maior pontuação percentual. 
Os dados foram submetidos à análise de variância (ANAVA) pelo Teste "F" ao nível de 5\% probabilidade. Para os fatores qualitativos foram realizados o Teste de Tukey a 5\%. As análises foram processadas no programa estatístico SISVAR versão 5.6 (Ferreira, 2011).

\section{Resultados e discussão}

Os resultados das amostras de colostro analisados por refratometria \%Brix de cadelas submetidas a parto eutócico e cesariana encontram-se na Figura 1. Os valores médios, mínimos e máximos para parto normal e cesariana foram de 25,25 - 29,45 e 24,12 - 29,16 de \% Brix, respectivamente, representando valores superiores aos encontrados por Mila et al. (2015) de \%Brix de $18.2 \pm 3,9$ com uma concentração de IgG significativa, de amostras de colostro de 44 cadelas de parto normal, observaram que que a média de concentração de IgG no colostro das glândulas mamárias anterior não foram significativamente diferente das posteriores, seja qual for o tamanho da cadela. Importante ressaltar que com a determinação da concentração da proteína total, pode-se determinar indiretamente a falha na transferência passiva de imunidade, e assim tomar medidas importantes a fim de se administar colostro ou outras fontes de imunoglobulinas para proteger a ninhada e assegurar a sobrevivência nas primeiras semanas de vida (Grongnet et al., 1996; Miagava et al., 2015). Deve-se também considerar as observações de Miagava et al. (2015) que relatam que as globulinas do colostro representam 72,54\% das proteínas totais, sendo que as imunoglobulinas compôem as globulinas que fornecem a imunidade passiva dos neonatos.
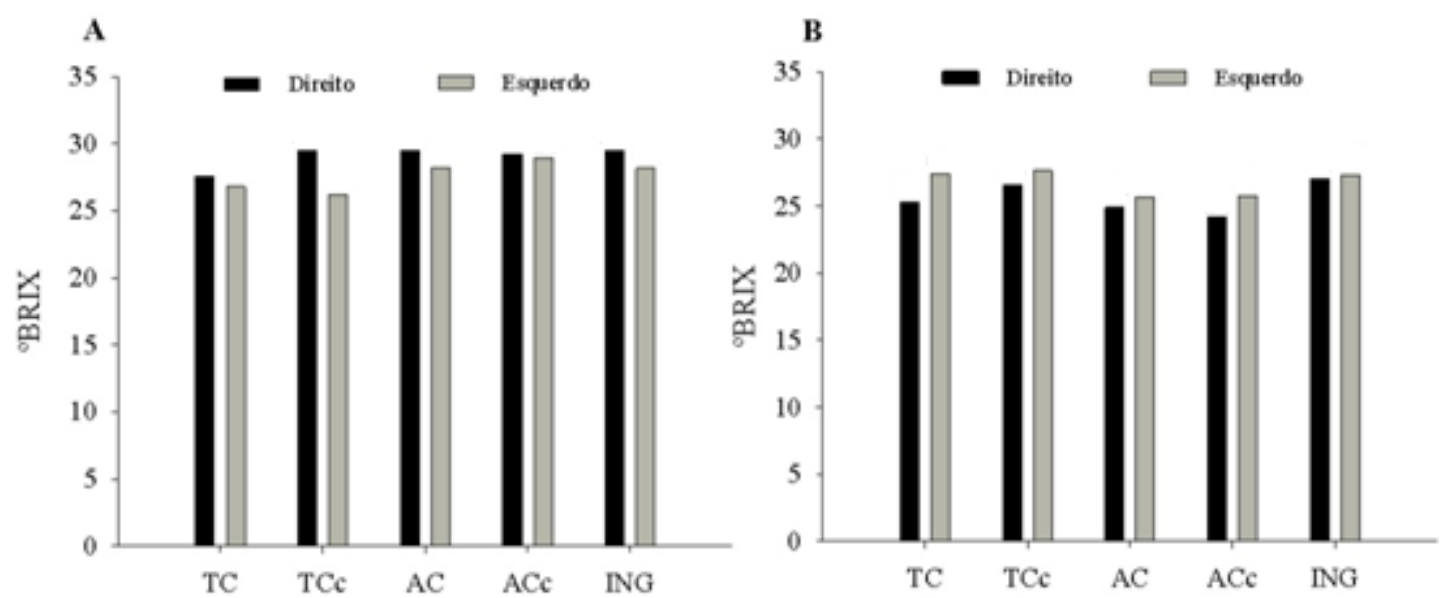

Figura 1. Estimativa de proteina total no colostro de cadelas coletados das tetas dos antímeros Direito (D) e Esquerdo (E) por refratometria \% Brix, submetidas a parto normal (A) e cesariana (B). (TC- teta toracica cranial; TCc - teta toracica cranio caudal; AC- teta abdominal cranial; Acc- teta abdominal cranio caudal; ING- teta inguinal).

Os resultados deste estudo na avaliação do colostro coletados em diferentes tetas dos antímeros direito e esquerdo nas cadelas submetidas ao parto normal e cesariana observou-se que não houve diferença $(\mathrm{P}>0,05)$ na média dos valores de proteína total avaliada pela refratometria, independentemente da posição das tetas e do antímero localizadas no abdômen. No entanto, resultados contraditórios foram encontrados por Mila et al. (2015) que relatam que existe grande variabilidade do contéudo de imunoglobulinas entre cadelas, mas também difere das glândulas mamárias em uma mesma fêmea sendo essa possível razão para justificar a inadequada transferência de imunuidade passiva para alguns filhotes e consequetemente a mortalidade neonatal. Chucri et al. (2010) afirmam que as fêmeas em parto eutócico e distócico garantem a proteção aos seus filhotes, pois a transferência de imunidade passiva da mãe para o feto ou recém-nascido é adquirida naturalmente através da transferência placentária ou ingestão do colostro, promovendo um imediato e temporário estado de imunidade.

Ao final da gestação, os anticorpos concentram-se na secreção da glândula mamária e derivam principalmente da circulação sanguínea ( $\operatorname{IgG})$ ou própria glândula mamária, sendo secretados no colostro e assim os neonatos têm a habilidade de absorver os anticorpos nas primeiras 24 horas de vida. As globulinas do colostro representam $72,54 \%$ das proteínas totais e as imunoglobulinas compõem as globulinas que fornecem a imunidade passiva aos neonatos, sendo, portanto, um dado importante. No entanto, esses resultados demonstram ser grande relevância para acompanhamento da imunidade dos filhotes de cadelas submetidas ao parto de cesariana. Devendo-se considerar que a determinação da 
concentração de imunoglobulinas no colostro é influenciada por diversos fatores como idade, nutrição, sanidade, estímulo antigênico, e também da técnica utilizada na sua detecção (Miagava et al., 2015). Pesquisas relacionadas sobre a concentração de imunoglobulinas contidas no colostro em animais, tem sido de grande valia, para que se possam ter informações da qualidade do colostro no período aonde o recém-nascido irá consumi-lo, até que se chegue a uma adaptação ao ambiente externo em que se encontra (Santos et al., 1994; Santos et al., 1988; Santos et al., 1995; Turquino et al., 2011).

No que se refere à técnica usada neste estudo, sabe-se que a transferência de imunidade passiva pode ser avaliada de uma forma direta pela quantificação de imunoglobulinas, ou de uma forma indireta pela medição de alguns parâmetros que se correlacionam com o nível de imunidade. Estes testes podem ser aplicados nos neonatos, obtendo de uma forma mais segura à imunidade do animal, ou serem usados no colostro, estimando assim a qualidade do colostro (Alves et al., 2015). Então se optou por uso de equipamento que fosse de baixo custo e fácil de realizar a avaliação, como apresentado pelo refratômetro, um instrumento que vem recentemente sendo utilizado na agropecuária para auxiliar neonatologia animal. Este aparelho por sua vez, é comumente utilizado para avaliar o teor de sacarose, e quando utilizado em fluido que não contém sacarose, faz uma estimativa da porcentagem de sólidos totais do conteúdo (Balzani et al., 2016).

Pode-se concluir que o método de refratometria utilizado neste estudo demonstrou ser prático, apresenta custo baixo e de fácil realização, podendo ser facilmente utilizado. Além disso, permitiu verificar que a qualidade do colostro nos diferentes pares de tetas de cadelas não apresenta diferenças significativas e não sofre efeito do tipo de parto.

\section{Referências bibliográficas}

Alves, A. C., Alves, N. G., Ascari, I. J., Junqueira, F. B., Coutinho, A. S., Lima, R. R. \& Abreu, L. R. (2015). Colostrum composition of Santa Inês sheep and passive transfer of immunity to lambs. Journal of Dairy Science, 98(6):3706-3716.

Balzani, A., Cordell, H. J. \& Edwards, S. A. (2016). Evaluation of an on-farm method to assess colostrum IgG content in sows. Animal, 10(4):643-648.

Chastant-Maillard, S., Freyburger, L., Marcheteau, E., Thoumire, S., Ravier, J. \& Reynaud, K. (2012). Timing of the intestinal barrier closure in puppies. Reproduction in Domestic Animals, 47190-193.

Chucri, T. M., Monteiro, J. M., Lima, A. R., Salvadori, M. L. B., Kfoury Junior, J. R. \& Miglino, M. A. (2010). A review of immune transfer by the placenta. Journal of Reproductive Immunology, 87(12):14-20.

Deelen, S. M., Ollivett, T. L., Haines, D. M. \& Leslie, K. E. (2014). Evaluation of a Brix refractometer to estimate serum immunoglobulin $\mathrm{G}$ concentration in neonatal dairy calves. Journal of Dairy Science, 97(6):3838-3844.

Feitosa, F. L. F. (2014). Semiologia veterinária: A arte do diagnóstico. São Paulo: Grupo Gen-Editora Roca Ltda.

Ferreira, D. F. (2011). SISVAR: A Computer Statistical Analysis System. Ciência e Agrotecnologia, 35(6):1039-1042.

Grongnet, J. F., Santos, G. T., Piot, M. \& Toullec, R. (1996). Influence of some food additives on IgG plasma concentrations in newborn calves fed an immunoglobulin solution extracted from colostrum. Lait, 76(3):303-309.

Miagava, K., Prestes, N. C., Moya-Araújo, C. F. \& Flagiari, J. J. (2015). Avaliação da qualidade imunológica do colostro e do soro sanguíneo de cadelas recém-páridas por diferentes métodos. Revista Portuguesa de Ciências Veterinárias, 11099-102.

Mila, H., Feugier, A., Grellet, A., Anne, J., Gonnier, M., Martin, M. \& Chastant-Maillard, S. (2015). Immunoglobulin $\mathrm{G}$ concentration in canine colostrum: Evaluation and variability. Journal of Reproductive Immunology, 11224-28.

Neves, T. A., Silva, C. C., Almeida, T. S., Sousa, I. V. P., Dias, F. E. F., Silva, C. M. G. \& Cavalcante, T. V. (2018). Colostro de ovelhas: Uma avaliação da qualidade por refratometria digital. Paper 
presented at the Anais I Congresso regional de sanidade animal e saúde pública e XI Semana Acadêmica de medicina Veterinária, Araguaína, Tocantins.

Quigley, J. D., Lago, A., Chapman, C., Erickson, P. \& Polo, J. (2013). Evaluation of the Brix refractometer to estimate immunoglobulin G concentration in bovine colostrum. Journal of Dairy Science, 96(2):1148-1155.

Santos, G. T., Bertolini, D. A., Macedo, F. A. F., Prado, I. N. \& Martins, E. N. (1994). Variabilidade em imunoglobulina $\mathrm{G}(\mathrm{IgG})$ no colostro de cabra de primeira ordenha e absorção intestinal de IgG pelos cabritos recém-nascidos. Brazilian Archives of Biology and Technology, 37(2):285-292.

Santos, G. T., Grongnet, J. F., Prado, I. N. \& Lareynie, J. (1988). Efeito da ordem de lactação sobre os níveis em imunoglobulinas $\mathrm{G}$ (IgG) do colostro bovino. Revista UNIMAR, 10(1):31-38.

Santos, G. T., Macedo, F. A. F., Bertolini, D. A., Prado, I. N. \& Martins, E. N. (1995). Produção e níveis de IgG no colostro de cabra SRD e absorção intestinal de IgG pelos cabritos recém-nascidos. Brazilian Archives of Biology and Technology, 24989-997.

Tôrres, A. M. \& Zimmermann, M. (2017). Transferência de imunidade passiva em cães e gatos neonatos. Revista Científica do Curso de Medicina Veterinária-FACIPLAC, 3(1):12-26.

Turquino, C. F., Flaiban, K. K. M. C. \& Lisbôa, J. A. N. (2011). Transferência de imunidade passiva em cordeiros de corte manejados extensivamente em clima tropical. Pesquisa Veterinária Brasileira, 31(3):199-205.

Vallet, J. L., Miles, J. R. \& Rempel, L. A. (2013). A simple novel measure of passive transfer of maternal immunoglobulin is predictive of preweaning mortality in piglets. The Veterinary Journal, 195(1):9197.

Recebido: 18 de julho, 2019.

Aprovado: 8 de outubro, 2019.

Publicado: 19 de dezembro, 2019.

Licenciamento: Este artigo é publicado na modalidade acesso aberto sob a licença Creative Commons Atribuição 4.0 (CC-BY 4.0), a qual permite uso irrestrito, distribuição, reprodução em qualquer meio, desde que o autor e a fonte sejam devidamente creditados. 